\title{
Kajian Pustaka Terstruktur Mengenai Analisis Audio Menggunakan Filterisasi Dengan Python
}

\author{
Nadea Cipta Laksmita ${ }^{1)}$, Arief Setyanto ${ }^{2)}$, Ferry Wahyu Wibowo ${ }^{3)}$ \\ 1,2,3 Universitas Amikom Yogyakarta \\ ${ }^{1,2,3}$ Gedongkiwo, MJI/887A, Ngringin, Condongcatur, Depok, Sleman \\ 1nadea.1195@students.amikom.ac.id, 2arief_s@amikom.ac.id, ${ }^{3}$ ferry.w@amikom.ac.id
}

\begin{abstract}
Abstrak
Kemajuan teknologi berkembang sangat pesat saat ini, ini dibuktikan dengan banyaknya aktifitas manusia yang menggunakan teknologi. Informasi audio sangat penting dalam peningkatan konten digital, sehingga diperlukan metodologi yang secara otomatis menganalisis. Dunia audio pada era digital memang sangat erat kaitannya dengan teknologi, karena audio dapat diubah menjadi sinyal digital sedemikian rupa bagi para pelaku nya, sehingga dalam hal ini dapat memanfaatkan filterisasi dengan Python yang merupakan metode yang lebih cepat, dan lebih efisien yang dapat dimanfaatkan untuk menganalisis dan eksperimen lainnya dalam bidang audio. Python adalah Bahasa pemrograman interpretative multiguna dengan filososfi perancangan yang berfokus pada tingkat keterbacaan kode. Dengan menggunakan Pyaudio yang difungsikan untuk penyajian pustaka Python yang terbuka sebagai prosedur analisis audio yang akan mengarah pada peningkatan praktis perpustakaan. Kajian Pustaka ini digunakan untuk menganalisis filterisasi pada audio yang akan dikembangkan pada musik gamelan dengan filterisasi IIR dan FIR yang menunjukkan bahwa akan menganalisis dan mampu membuat performa audio menjadi maksimal.
\end{abstract}

Kata kunci:filtering, python, pyaudio, analisis, audio

\section{PENDAhuluan}

Digital recording mulai menggantikan sistem analog recording dalam proses audio recording sebelum tahun 1976, semua musik direkam menggunakan analog tape recorder, dimana sinyal audio direkam sebagai pola naik dan turun menjadi gelombang sinyal. Dengan menggunakan teknologi pekerjaan dapat diselesaikan dengan waktu yang lebih cepat dan juga menghemat biaya. Informasi audio sangat penting dalam peningkatan konten digital, sehingga diperlukan metodologi yang secara otomatis menganalisis. Dunia audio pada era digital memang sangat erat kaitannya dengan teknologi, karena audio dapat diubah menjadi sinyal digital sedemikian rupa bagi para pelaku. Ketika kita melakukan perekaman sebuah suara, tidak jarang karena sudah banyak sekali aplikasi/software perekaman yang digunakan kemudian menampilkan, menambah hasil atau informasi secara cepat dan instan tanpa mengetahui proses penghitungan pada penambahan atau pengurangan informasi digital suatu audio. Sangat penting mengingat bahwa peningkatan kualitas digital teknologi yang sangat erat dengan teknis.

Filtering digunakan pada perangkat audio untuk membersihkan sinyal suara, agar suara yang terdengar lebih jernih. Kita ketahui bahwa sinyal audio atau suara yang dapat didengar oleh telinga manusia adalah dengan frekuensi $20 \mathrm{~Hz}$ sampai dengan $20 \mathrm{KHz}$ sehingga frekuensi pada ukuran berapa yang akan didengarkan. Filterisasi dengan digital adalah salah satu yang cukup penting dari sebuah proses sinyal digital, yang digunakan untuk kalkulasi terhadap rentang angka sample dari sinyal digital tersebut. Banyak sekali transformasi sinyal namun filtering digunakan karena dapat bekerja dengan baik pada rentang frekuensi anatara $20 \mathrm{H}-20 \mathrm{KHz}$. Perkembangan teknologi ini memiliki manfaat yang sangat besar terlebih bidang audio ini guna menjadikan sebuah parameter baru bagi praktisi audio dengan mengikuti proses pengolahan audio dengan lebih kuantitatif dan menghasilkan audio yang kualitatif. Terdapat 2 jenis filterisasi yang akan digunakan peneliti untuk diterapkan dalam penelitiannya yaitu Finite Impulse Response Filters (FIR) atau respon integral terhadap selang waktu 
bekerjanya gaya dari penyaringan tak terbatas, dan Infinite Impulse Response Filters (IIR) atau respon integral terhadap selang waktu bekerjanya gaya dari penyaringan terbatas. Dengan filterisasi tersebut akan mengoptimalkan proses penelitian dalam audio menjadi lebih baik.

Komputer menjadi peran sangat penting sebagai pusat yang hampir semua berhubungan dengan audio. Baik dalam produksi musik, perekaman di studio atau pencampuran suara secara langsung. Efek audio, plugin dan instrumen virtual diterapkan dengan kode perangkat lunak komputer. Aplikasi musik adalah program yang dijalankan pada komputer juga. Dengan demikian semua alat ini dibuat dengan menggunakan program komputer. Informasi audio memainkan peran yang agak penting dalam peningkatan konten digital yang tersedia pada saat ini, menghasilkan kebutuhan akan metologi yang secara otomatis menganalisis konten tersebut. Python adalah Bahasa pemrograman open source yang berjalan di banyak platform termasuk Linux,Mac OS X dan Windows. Secara luas digunakan dan dikembangkan secara aktif dan memiliki beragam kode perpustakaan dan alat pengembangan, dan yang akan terintegrasi dengan baik dengan banyak bahasa pemrograman lain, dan aplikasi musik. Pyaudio adalah pustaka Python open source yang menyediakan berbagai prosedur analisis audio seperti ekstraksi fitur, klasifikasi sinyal audio, segmentasi yang diawasi dan tanpa pengawasan dan visualisasi konten. Pyaudio telah digunakan dalam beberapa aplikasi peneltian analisis audio seperti fungsi rumah pintar melalui deteksi peristiwa audio, pengenalan emosi ucapan, klasifikasi depresi berdasarkan fitur audio-visual, segmentasi musik, rekomendasi film berbasis konten multimoda dan aplikasi kesehatan (misalnya memantau makan kebiasaan). Umpan balik yang disediakan dari semua aplikasi audio khusus ini telah mengarah pada peningkatan praktis perpustakaan. Penulis menggunakan alat ini untuk penelitiannya audio pada perekaman langsung musik gamelan.

Paper ini ditulis agar memberikan referensi atau wawasan terhadap peneliti terhadap penggunaan filterisasi $F I R$ dan IIR yang diterapkan menggunakan Python sebagai Analisa terhadap audio. Ada beberapa saat ini model filterisasi yang digunakan untuk menganalisa audio yang sering diterapkan pada file musik, dengan harapansetelah mendapatkan wawasan tentang penggunaan filterisasi pada Python. Peneliti dapat mengetahui hasil analisa dari filerisasi dengan emnggunakan Python dan mampu mengembangkannya, sehingga akan sangat bermanfaat untuk pelaku peneliti bidang audio.

\section{METODE PENELITIAN}

Metode penelitan yang ditetapkan ini disusun sesuai dengan kajian yang dilakukan pada saat pelaksanaan penelitian akan berjalan dengan baik.

\section{a. Alur Pengkajian Pustaka}

Alur pengkjian pustaka dilakukan agar dalam melakukan penelitian dapat memperleh hasil yang baik. Karena penelitian sebeleumnya telah mendapat respon ketika diterbitkan. Terlebih pada analisis audio ini, semua harus dilakukan dengan sesuai.

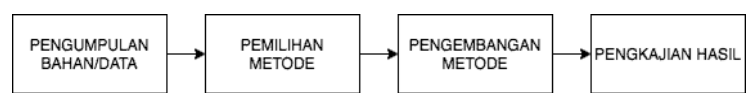

Gambar 1. Alur Pengkajian Pustaka

\section{b. Metode Penelitian}

Klasifikasi mungkin merupakan masalah terpenting dalam aplikasi pembelajaran mesin. Ini merujuk pada tugas mengklasifikasikan sampel yang tidak diketahui (dalam kasus sinyal audio kami) ke sekumpulan kelas yang telah ditentukan, menurut beberapa model yang diawasi yang terlatih. Perpustakaan menyediakan fungsionalitas untuk pelatihan model yang dilindungi yang mengklasifikasikan baik segmen atau seluruh rekaman audio. Mesin vektor pendukung dan pengklasifikasi kNearest Neighbor telah diadopsi untuk tujuan ini. Selain itu, prosedur validasi silang disediakan untuk mengekstrak pengklasifikasi dengan parameter yang dioptimalkan. Secara khusus, tingkat presisi dan perolehan, bersama dengan ukuran F1 diekstraksi per kelas audio. Pemilihan parameter dilakukan berdasarkan pengukuran F1 rata-rata terbaik.Fungsi pembungkus tingkat tinggi disediakan sehingga proses ekstraksi fitur juga tertanam dalam prosedur klasifikasi. Dengan cara ini, pengguna dapat secara langsung mengklasifikasikan file audio yang tidak 
dikenal atau bahkan grup file audio yang disimpan di jalur tertentu.

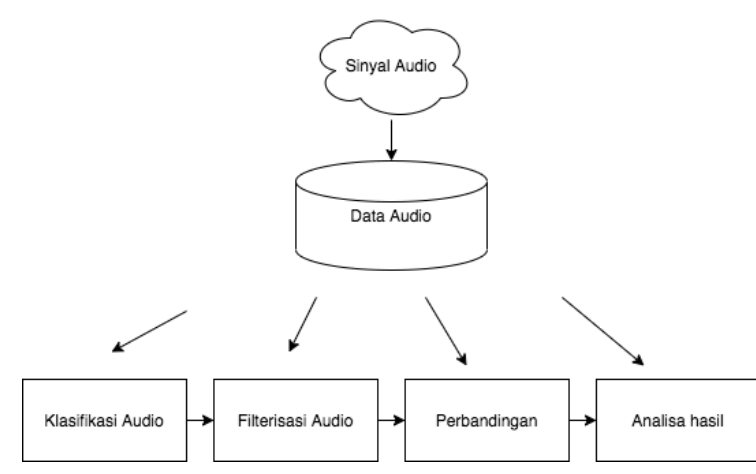

Gambar 2. Metode Penelitian

Filter digital merupakan algoritma matematika yang diimplementasikan dalam bentuk hardware atau software yang beroperasi pada sinyal input digital menghasilkan output berupa sinyal output digital untuk mencapai sasaran pemfilteran. Filter digital memiliki banyak keunggulan untuk beberapa aplikasi (seperti data compressing, biomedical signal processing, speech processing, image proceesing, data transmission, digital audio) dikarenakan filter digital dapat mempunyai karakteristik yang tidak mungkin dimiliki oleh filter analog yaitu linier phase response yang sempurna.

\section{TINJAUAN PUSTAKA}

Analisis audio dengan filterisasi khususnya pada musik gamelan membutuhkan data audio format .wav karena data tersebut belm terjadi suatu perubahan yang besar dan utuh serta optimal ketika dilakukan sebuah penambahan informasi berupa filterisasi. Data audio gamelan diambil dari perekaman secara langsung yang tidak banyak orang memiliki file tersebut guna dijadikan bahan penelitian.

Penelitian ini dipusatkan pada kajian pustka dari berbagai penelitian yang sebelumnya berhubungan dengan topik serupa yang akan diteliti yaitu filterisasi audio. Tujuan dari dilakukan penelitian ini adalah agar mengetahui pengembangan metode filterisasi yang proper untuk menganalisis audio secara efktif dan efisien serta yang terkandung dari hasil penelitian adalah pengembangan dari metodenya. Kajian pustaka inimeliputi pengumpulan bahan/data, penerapan metode filterisasi, pengembangan metode yang diambil, lalu hasil dari penelitian sebelumnya. Setelahnya peneliti akan melakukan pembahasan secara mendalam pada penelitian sebelumnya yang sudah dikaji. Ini akan bermanfaat bagi peneliti pada bidang audio yang akan melakukan analisis.Dalam analisis derau sangat banyak jenisnya, salah satunya yang digunakan adalah thermal noise berhubungan dengan perpindahan elektron yang cepat dan acak dalam alat konduktor akibat digitasi thermal membuktikan bahwa kekuatan thermal noise proporsional dengan bandwidth dan temperatur absolut.

$\mathrm{N}=\mathrm{KTB}$

Keterangan:

$\mathrm{N}=$ kekuatan noise (noise power)

$\mathrm{K}=$ Boltzmann's proportionality constant (1.38

$\times 10-23$ joules per Kelvin)

$\mathrm{T}=$ Temperatur absolute

$\mathrm{B}=$ bandwidth

\section{HASIL DAN PEMBAHASAN}

Dalam audio perancangan filter $F I R$ dengan fungsi window yang mengubah nilai variabel. Perbandingan yang diambil adalah window Hamming dan Kaiser yang digunakan untuk mengolah sinyal digital. Hasilnya memiliki respons fase linier yang bagus untuk menentukan krteria paling penting untuk filter FIR tersebut dapat disesuaikan dengan mengubah nilai suatu variabel. Dalam makalah ini kami telah menyajikan pyAudioAnalysis, pustaka Python opensource yang mengimplementasikan berbagai fungsi analisis audio dan dapat digunakan di beberapa aplikasi. Dengan menggunakan pyAudioAnalysis, seseorang dapat mengklasifikasikan segmen audio yang tidak diketahui menjadi sekumpulan kelas yang telah ditentukan, mengelompokkan rekaman audio dan mengklasifikasikan segmen yang homogen, menghapus area hening dari rekaman ucapan, memperkirakan emosi segmen ucapan, mengekstrak thumbnail audio dari trek musik, dll. Wrappers tingkat tinggi dan penggunaan baris perintah juga disediakan sehingga non-programmer dapat mencapai fungsionalitas penuh. Rentang fungsi analisis audio yang diterapkan di perpustakaan mencakup sebagian besar spektrum analisis audio umum: klasifikasi, regresi, segmentasi, deteksi perubahan, pengelompokan dan visualisasi melalui pengurangan dimensi. Oleh karena itu pyAudio dapat digunakan sebagai dasar untuk 
sebagian besar aplikasi analisis audio umum. PyAudio terus ditingkatkan dan komponen baru akan ditambahkan dalam waktu dekat. Secara khusus, arahan utama yang sedang berlangsung adalah: (a) implementasi fungsi sidik jari audio yang akan diadopsi dalam konteks sistem pengambilan audio (b) mengoptimalkan semua fungsi ekstraksi fitur dengan mempercepat fungsi-fungsi kritis menggunakan paralelisasi GPU NVIDIA melalui pemrograman Cuda.

Filter digital adalah wajib bagi pemrosesan sinyal digital. Hal ini disajikan filter digital yang menghilangkan sinyal atau kebisingan yang tidak diinginkan dari sinyal yang dperlukan dan meningkatkan kinerja sinyal yang lebih baik. Diberikan parameter dari filter IIR untuk mencapai hasil yang diinginnkan. Dengan perangkat lunak MATLAB FDA yang digunakan sebagai pencarian berbagai respons filter digital, sehingga akan mengerti parameter analisis respons fase, respons langkah dan impuls daripada filter tersebut. Beberapa sinyal audio yang dipilih digunakan untuk mengamati respons empiris dari high pass, low pass, band stop filter dan band pass filter. Namun implementasi langsng dari respons ruang umumnya tidak praktis karena kompleksitas dinamika sistem yang ekstream. Sehingga dilakukan sebuah implementasiteknik IRR filter yang disintesis dengan sub-band, sehingga terbukti efektif dalam memeberikan reproduksi kualitas gema pada ruangan.

Filter adalah jaringan yang memproses sinyal dengan cara bergantung pada frekuensi. Filter menyaring dan menghilangkan noise dari audio, dan dalam penelitian ini penulis juga mengikuti metode deskriptif analitik. Filter yang digunaka adalah low pass filter dengan pengambilan sampel audio berformat .wav yang melakukan operasi penyaringan dengan perhitungan persamaan perbedaan. Persamaan koefisien dan fungsi sebagai low pass diberikan agar optimal dalam pengunaannya.

Tabel 1. Perbandingan Proses Tinjauan

\begin{tabular}{|c|l|l|l|}
\hline $\begin{array}{c}\text { Refere } \\
\text { nsi } \\
\text { Paper }\end{array}$ & Tujuan Paper & Kesimpulan & $\begin{array}{l}\text { Saran atau } \\
\text { Kelemahan }\end{array}$ \\
\hline 1. & $\begin{array}{l}\text { Perancangan } \\
\text { filter FIR } \\
\text { dengan wndow } \\
\text { baru,karena } \\
\text { dapat } \\
\text { mengubah nilai }\end{array}$ & $\begin{array}{l}\text { Dari } \\
\text { keseluruhan } \\
\text { penelitian } \\
\text { dapat } \\
\text { disimpulkan } \\
\text { bahwa jendela }\end{array}$ & $\begin{array}{l}\text { FIR filter } \\
\text { hanya } \\
\text { dapat } \\
\text { memungki } \\
\text { nkan untuk } \\
\text { method }\end{array}$ \\
\hline
\end{tabular}

\begin{tabular}{|c|c|c|c|}
\hline & $\begin{array}{l}\text { variabel, dan } \\
\text { dapat } \\
\text { disesuaikan. } \\
\text { FIR merupakan } \\
\text { filter digital } \\
\text { dengan cara } \\
\text { windowing, } \\
\text { fungsi dua } \\
\text { parameter yang } \\
\text { dapat } \\
\text { disesuaikan } \\
\text { sesuai dengan } \\
\text { kebutuhan } \\
\text { sehingga dapat } \\
\text { dihasilkan } \\
\text { suatu analisis } \\
\text { dari sinyal } \\
\text { digital. }\end{array}$ & $\begin{array}{l}\text { yang diusulkan } \\
\text { cukup efisien } \\
\text { di atas window } \\
\text { hamming \& } \\
\text { Kaiser, di } \\
\text { mana rasio } \\
\text { roll-off sisi- } \\
\text { lobus untuk } \\
\text { jendela yang } \\
\text { diusulkan } \\
\text { adalah } \\
\text { 24,65dB } \\
\text { sedangkan } \\
\text { jendela } \\
\text { hamming \& } \\
\text { Kaiser masing- } \\
\text { masing } \\
\text { memiliki } \\
\text { 5,74dB, } \\
\text { 18,87dB. } \\
\text { Selain dalam } \\
\text { kasus filter } \\
\text { FIR, } \\
\text { menggunakan } \\
\text { jendela yang } \\
\text { diusulkan, } \\
\text { memiliki rasio } \\
\text { roll-off sisi- } \\
\text { lobus 24,78dB } \\
\text { di mana untuk } \\
\text { hamming dan } \\
\text { jendela Kaiser } \\
\text { masing-masing } \\
\text { 5,71dB \& } \\
\text { 18,76 dB yang } \\
\text { menyiratkan } \\
\text { bahwa jendela } \\
\text { yang diusulkan } \\
\text { lebih efisien } \\
\text { daripada } \\
\text { hamming dan } \\
\text { Kaiser jendela. } \\
\text { Selain itu, dari } \\
\text { keseluruhan } \\
\text { penelitian, } \\
\text { dipahami } \\
\text { bahwa jendela } \\
\text { yang diusulkan } \\
\text { memiliki fase } \\
\text { respons fase } \\
\text { linier yang } \\
\text { baik, yang } \\
\text { merupakan } \\
\text { salah satu } \\
\text { kriteria paling } \\
\text { penting untuk } \\
\text { filter FIR \& } \\
\text { jendela } \\
\text { tersebut dapat } \\
\text { disesuaikan } \\
\text { dengan } \\
\text { mengubah nilai } \\
\text { suatu variabel. }\end{array}$ & $\begin{array}{l}\text { window, } \\
\text { untuk } \\
\text { frekuensi } \\
\text { sampling } \\
\text { saja, lalu } \\
\text { filter hanya } \\
\text { memiliki } \\
\text { durasi } \\
\text { respons } \\
\text { impuls } \\
\text { yang } \\
\text { terbatas. } \\
\text { Sehingga } \\
\text { filter yang } \\
\text { diusulkan } \\
\text { lebih } \\
\text { efisien } \\
\text { daripada } \\
\text { Hamming } \\
\text { dan Kaiser. } \\
\text { Tidak } \\
\text { dispesifika } \\
\text { sikan } \\
\text { media dan } \\
\text { format } \\
\text { yang akan } \\
\text { dilakukan } \\
\text { filterisasi } \\
\text { apa. }\end{array}$ \\
\hline 2. & $\begin{array}{l}\text { Dalam } \\
\text { makalah } \\
\text { bertujuan } \\
\text { untuk } \\
\text { menyajikan } \\
\text { filter digital } \\
\text { yang dapat } \\
\text { menghilangkan } \\
\text { sinyal atau } \\
\text { kebisingan } \\
\text { yang tidak } \\
\text { diinginkan }\end{array}$ & $\begin{array}{l}\text { Dalam tulisan } \\
\text { ini, parameter } \\
\text { desain yang } \\
\text { berbeda telah } \\
\text { dipertimbangk } \\
\text { an untuk filter } \\
\text { IIR } \\
\text { Butterworth } \\
\text { untuk } \\
\text { menganalisis } \\
\text { kinerja filter. } \\
\text { Empat kategori }\end{array}$ & $\begin{array}{l}\text { Sinyal } \\
\text { Audio } \\
\text { yang } \\
\text { mengalami } \\
\text { filterisasi } \\
\text { tidak } \\
\text { semuanya } \\
\text { akan } \\
\text { menjadi } \\
\text { sinyal yang } \\
\text { lebih baik, } \\
\text { dikarenaka } \\
\end{array}$ \\
\hline
\end{tabular}




\begin{tabular}{|c|c|c|c|}
\hline & $\begin{array}{l}\text { untuk } \\
\text { meningkatkan } \\
\text { kinerja sinyal } \\
\text { digital yang } \\
\text { lebih baik dari } \\
\text { sebelumnya. } \\
\text { Dengan } \\
\text { Matlab, } \\
\text { diberikan } \\
\text { sebuah } \\
\text { parameter yang } \\
\text { dirancang } \\
\text { berbeda dari } \\
\text { filter IIR untuk } \\
\text { mencapai hasil } \\
\text { yang } \\
\text { diinginkan. }\end{array}$ & 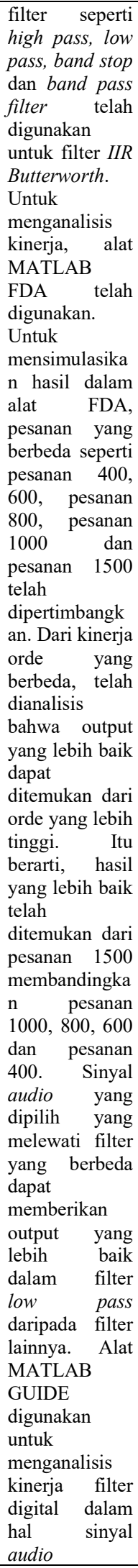 & $\begin{array}{l}\mathrm{n} \\
\text { kebutuhan } \\
\text { setiap } \\
\text { sinyal yang } \\
\text { akan } \\
\text { dirancang } \\
\text { berbeda- } \\
\text { beda. Kita } \\
\text { hanya bisa } \\
\text { menganalis } \\
\text { is sinyal } \\
\text { ketika } \\
\text { dilakukan } \\
\text { filtering. } \\
\text { Filter IIR } \\
\text { sulit } \\
\text { dikendalik } \\
\text { an dan } \\
\text { tidak } \\
\text { memiliki } \\
\text { fase } \\
\text { tertentu, } \\
\text { juga } \\
\text { memiliki } \\
\text { siklus } \\
\text { terbatas. } \\
\text { Filtr IIR } \\
\text { berasal } \\
\text { dari } \\
\text { analog. IIR } \\
\text { tidak } \\
\text { terbatas } \\
\text { dan } \\
\text { digunakan } \\
\text { untuk } \\
\text { aplikasi } \\
\text { dimana } \\
\text { karakteristi } \\
\text { k tinier } \\
\text { tidak } \\
\text { menjadi } \\
\text { acuan. }\end{array}$ \\
\hline 3. & $\begin{array}{l}\text { Aplikasi } \\
\text { perangkat } \\
\text { lunak untuk } \\
\text { Pemrosesan } \\
\text { Sinyal Digital } \\
\text { diimplementasi } \\
\text { kan dengan }\end{array}$ & $\begin{array}{l}\text { Sinyal audio } \\
\text { untuk menjadi } \\
\text { invarian, } \\
\text { nonlinier dan } \\
\text { dalam sinyal } \\
\text { homogen } \\
\text { memiliki }\end{array}$ & $\begin{array}{l}\text { Hanya } \\
\text { digunakan } \\
\text { data } m p 3 \\
\text { sebagai } \\
\text { inputan, } \\
\text { seharusnya } \\
\text { untuk } \\
\end{array}$ \\
\hline
\end{tabular}

\begin{tabular}{|c|c|c|}
\hline $\begin{array}{l}\text { perangkat } \\
\text { MyDAQ; } \\
\text { dalam aplikasi } \\
\text { yang } \\
\text { dirancang, } \\
\text { sinyal audio } \\
\text { dari File MP3 } \\
\text { digunakan } \\
\text { sebagai data } \\
\text { input. Alat } \\
\text { perangkat } \\
\text { lunak berbasis } \\
\text { Labview GUI } \\
\text { dikembangkan } \\
\text { untuk porpoise } \\
\text { ini untuk } \\
\text { memvisualisasi } \\
\text { kan respons } \\
\text { spektrum } \\
\text { frekuensi. Dua } \\
\text { filter khusus } \\
\text { sebagai } \\
\text { Respons } \\
\text { Impuls Tak } \\
\text { Terbatas (FIR) } \\
\text { atau (IIR) } \\
\text { Infinite } \\
\text { Impulse } \\
\text { Response } \\
\text { diimplementasi } \\
\text { kan dan } \\
\text { dibandingkan. } \\
\text { Prosedur dan } \\
\text { simulasi } \\
\text { dirancang } \\
\text { dalam Matlab } \\
\text { untuk } \\
\text { memahami } \\
\text { proses yang } \\
\text { dilakukan oleh } \\
\text { Digital Signal } \\
\text { Processor } \\
\text { (MyDSP) dari } \\
\text { Instrumen } \\
\text { Nasional } \\
\text { sebagai studi } \\
\text { kasus dalam } \\
\text { kegiatan } \\
\text { pendidikan. }\end{array}$ & 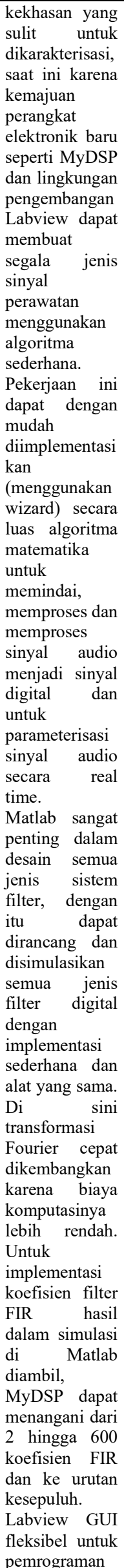 & $\begin{array}{l}\text { inputan } \\
\text { audio yang } \\
\text { lebih } \\
\text { proper } \\
\text { untuk } \\
\text { dijadikan } \\
\text { bahan } \\
\text { analisis } \\
\text { adalah } \\
\text { waveform } \\
\text { karena } \\
\text { tingkat } \\
\text { fleksibelita } \\
\text { s dan } \\
\text { sample rate } \\
\text { nya tinggi } \\
\text { untuk } \\
\text { dilakukan } \\
\text { sebuah } \\
\text { penyaringa } \\
\text { n }\end{array}$ \\
\hline
\end{tabular}




\begin{tabular}{|c|c|c|c|}
\hline & & 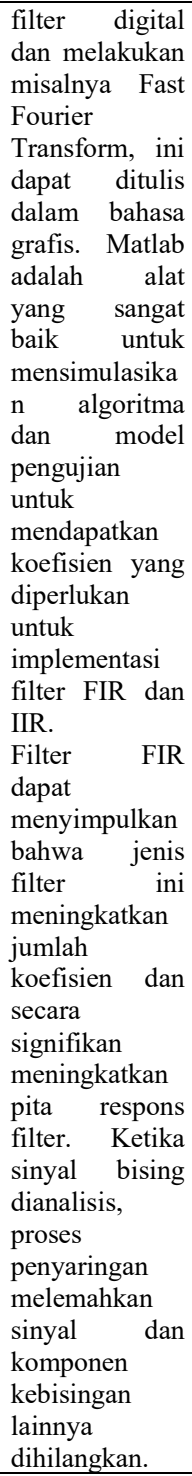 & \\
\hline 4. & $\begin{array}{l}\text { Dalam } \\
\text { penelitian ini, } \\
\text { sistem sound } \\
\text { surround soung } \\
\text { baru yang } \\
\text { dioperasikan } \\
\text { oleh papan } \\
\text { DSP } \\
\text { dikembangkan. } \\
\text { Selain woofer } \\
\text { (s) dan tweeter } \\
\text { (s), sistem } \\
\text { audio telah } \\
\text { ditingkatkan } \\
\text { dengan } \\
\text { menambahkan } \\
\text { speaker } \\
\text { tambahan } \\
\text { untuk } \\
\text { menangani } \\
\text { frekuensi } \\
\text { menengah } \\
\text { dengan } \\
\text { merancang } \\
\text { filter band-pass } \\
\text { tertentu untuk } \\
\text { memproses } \\
\text { mid-range-nya. } \\
\text { Sementara itu, }\end{array}$ & 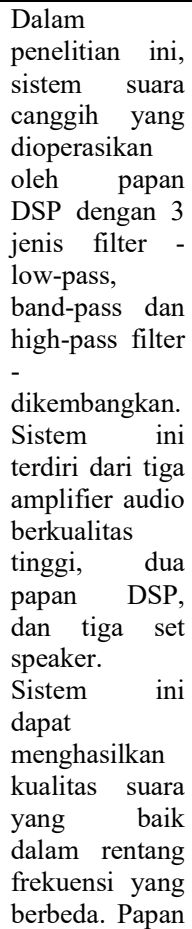 & $\begin{array}{l}\text { Dalam era } \\
\text { modern } \\
\text { seperti ini } \\
\text { akan } \\
\text { sangat } \\
\text { bagus jika } \\
\text { dibuat } \\
\text { penyaringa } \\
\text { n versi } \\
\text { digital di } \\
\text { mana penerapann } \\
\text { ya akan } \\
\text { sangat } \\
\text { dinamis }\end{array}$ \\
\hline
\end{tabular}

\begin{tabular}{|c|c|}
\hline 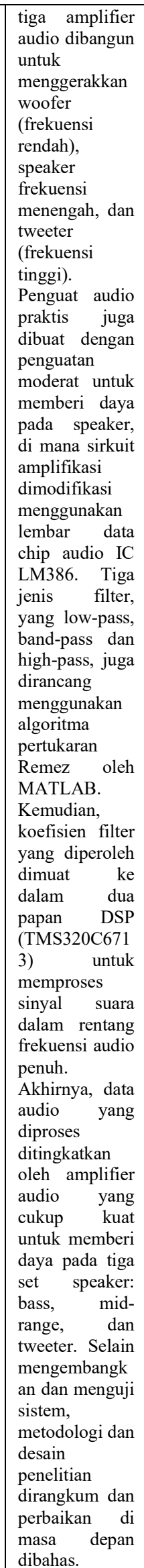 & $\begin{array}{l}\text { DSP karena itu } \\
\text { berhasil } \\
\text { digunakan } \\
\text { dalam } \\
\text { penyaringan } \\
\text { audio dan } \\
\text { terbukti } \\
\text { menawarkan } \\
\text { kualitas suara } \\
\text { yang tinggi. } \\
\text { Peningkatan di } \\
\text { masa depan } \\
\text { termasuk } \\
\text { membuat } \\
\text { amplifier yang } \\
\text { lebih kuat, } \\
\text { lebih banyak } \\
\text { saluran suara, } \\
\text { dan memberikan } \\
\text { efek surround. }\end{array}$ \\
\hline
\end{tabular}




\section{KESIMPULAN DAN SARAN}

Dalam makalah ini kami telah menyajikan pyAudioAnalysis, pustaka Python open-source yang mengimplementasikan berbagai fungsi analisis audio dan dapat digunakan di beberapa aplikasi. Dengan menggunakan pyAudioAnalysis, seseorang dapat mengklasifikasikan segmen audio yang tidak diketahui menjadi sekumpulan kelas yang telah ditentukan, mengelompokkan rekaman audio dan mengklasifikasikan segmen yang homogen, menghapus area hening dari rekaman ucapan, memperkirakan emosi segmen ucapan, mengekstrak thumbnail audio dari trek musik, dll. Wrappers tingkat tinggi dan penggunaan baris perintah juga disediakan sehingga nonprogrammer dapat mencapai fungsionalitas penuh. Rentang fungsi analisis audio yang diterapkan di perpustakaan mencakup sebagian besar spektrum analisis audio umum: klasifikasi, regresi, segmentasi, deteksi perubahan, pengelompokan dan visualisasi melalui pengurangan dimensi. Oleh karena itu pyAudio dapat digunakan sebagai dasar untuk sebagian besar aplikasi analisis audio umum. PyAudio terus ditingkatkan dan komponen baru akan ditambahkan dalam waktu dekat. Secara khusus, arahan utama yang sedang berlangsung adalah: (a) implementasi fungsi sidik jari audio yang akan diadopsi dalam konteks sistem pengambilan audio (b) mengoptimalkan semua fungsi ekstraksi fitur dengan mempercepat fungsi-fungsi kritis menggunakan paralelisasi GPU NVIDIA melalui pemrograman Cuda

\section{REFERENSI}

Mclughlin, I.(2009). Applied Speech and Audio Processing: with Matlab Examples . Cambrid: University Press.

Giannakopoulos, T.(2014). Introduction to Audio Analysis: a MATLAB. Academic Press.

Tarr, E.(2018). Hack Audio: an Introduction to Computer Programmung and Digital Signal Processing in MATLAB, Routledge.

Bai, M. R., Ou, K. Y., \& Zeung, P.(2009). Multirate synthesis of reverberators using subband filtering. Journal of sound and vibration, 321(3-5), 1090-1108.

Dornean, I., Topa, M., Kirei, B. S., \& Neag, M., (2009). Sub-band adaptive filtering for acoustic echo cancellation. In 2009
European Conference on Circuit Theory and Design (pp. 810-813). IEEE.

Jiang, J.(2018). Audio processing with channel filtering using DSP techniques. In 2018 IEEE 8th Annual Computing and Communication Workshop and Conference (CCWC) (pp. 545-550). IEEE.

Meiniar, W., Afrida, F. A., Irmasari, A., Mukti, A., \& Astharini, D.(2017). Human voice filtering with band-stop filter design in MATLAB. In 2017 International Conference on Broadband Communication, Wireless Sensors and Powering (BCWSP) (pp. 1-4). IEEE.

Salih, A. O. M.(2017). Audio Noise Reduction Using Low Pass Filters. Open Access Library Journal, 4(11), 1-7.

Serrezuela, R. R., Chavarro, A. F., Cardozo, M. A. T., Caicedo, A. G. R., \& Cabrera, C. A., (2017). Audio signals processing with digital filters implementation using MyDSP. ARPN Journal of Engineering and Applied Sciences, 12(16), 4848-4853.

Shil, M., Rakshit, H., \& Ullah, H.(2017). An adjustable window function to design an FIR filter. In 2017 IEEE International Conference on Imaging, Vision \& Pattern Recognition (icIVPR) (pp. 1-5). IEEE.

Sutradhar, S. R., Sayadat, N., Rahman, A., Munira, S., Haque, A. F., \& SAKIB, S. N.(2017). IIR based digital filter design and performance analysis. In 2017 2nd International Conference on Telecommunication and Networks (TELNET) (pp. 1-6). IEEE. 